\title{
A CITOGENÉTICA DO ESPERMATOZÓIDE HUMANO: TÉCNICA DE FERTILIZAÇÃO IN VITRO, HETERÓLOGA, HOMEM/HAMSTER
}

\author{
CYTOGENETICS OF HUMAN SPERMATOZOA: HUMAN/HAMSTER \\ IN VITRO FERTILIZATION TECHNIQUE
}

Elza M.P. Sartorelli', Wagner J.M. Paiva², Luiz F. Mazzucato³ \& João M. Pina-Neto4

\begin{abstract}
${ }^{1}$ Aluna do curso de pós-graduação do Departamento de Genética e Matemática Aplicada à Biologia, da Faculdade de Medicina de Ribeirão Preto da Universidade de São Paulo e Docente do Departamento de Biologia Celular, Embriologia e Genética do Centro de Ciências Biológicas da Universidade Federal de Santa Catarina; ${ }^{2}$ Docente do Departamento de Genética da Universidade Estadual de Londrina; ${ }^{3}$ Biólogo, técnico do Laboratório de Citogenética do Departamento de Genética e Matemática Aplicada à Biologia e ${ }^{4}$ Médico Geneticista do Hospital das Clínicas de Ribeirão Preto e Docente - Faculdade de Medicina de Ribeirão Preto da Universidade de São Paulo.

Correspondência: Prof.Dr. João Monteiro de Pina-Neto. Departamento de Genética e Matemática Aplicada à Biologia - Bloco D da Faculdade de Medicina de Ribeirão Preto da Universidade de São Paulo - CEP: 14049-900 - Ribeirão Preto - SP, Fone: (016) 602.3104 Fax: (016) 633.0069
\end{abstract}

SARTORELLI EMP; PAIVA WJM; MAZZUCATO LF. \& PINA-NETO JM. A citogenética do espermatozóide humano: técnica de fertilização in vitro, heteróloga, homem/hamster. Medicina, Ribeirão Preto, 32: 159-166, abr.jun. 1999.

RESUMO: A constituição cromossômica do espermatozóide humano pode ser estudada, atualmente, através da técnica de fertilização "in vitro" (FIV), heteróloga, homem/hamster. Essa técnica permite a individualização dos cromossomos do espermatozóide humano, possibilitando a análise de suas anomalias numéricas e estruturais. $O$ aprimoramento dessa técnica estimulou um novo campo de pesquisa na Citogenética Humana e na Genética Clínica. Sua implantação em nosso laboratório na Faculdade de Medicina de Ribeirão Preto, Universidade de São Paulo, propiciará melhor estimativa da probabilidade de transmissão de anomalias cromossômicas por células da linhagem germinativa de homens em risco genético.

UNITERMOS: Espermatozóide. Humano. Cromossomos.

\section{INTRODUÇÃO}

As anomalias cromossômicas, transmitidas por células da linhagem germinativa contribuem significativamente para as perdas gestacionais, infertilidade, malformações congênitas e deficiência mental, evidenciando a relevância dos estudos dessas anomalias, suas origens, causas e mecanismos.

Na década de setenta (70), um grupo de pesquisadores ${ }^{(1)}$ interessados em desenvolver um sistema que permitisse estudar o processo de fertilização em mamíferos, inclusive a capacidade de fertilização de espermatozóides humanos, se defrontou com uma dificuldade: necessitariam encontrar um sistema que permitisse que esses espermatozóides penetrassem em oócitos, não humanos, para atingirem seus objetivos. Em 1976, esses pesquisadores ${ }^{(1)}$ demonstraram que o bloqueio de fertilização de oócitos de hamster dourado (Mesocricetus auratus) estava localizado na zona pelúcida e que, quando ela era removida, por digestão enzimática, muito pouco restava dessa especificidade e que espermatozóides humanos (assim como os de outras espécies de mamíferos), devidamente capacitados, penetravam nos mesmos. Dois anos depois, Rudak et al. ${ }^{(2)}$ descreveram uma nova metodologia que permitia estudar a constituição cromossômica de espermatozóides humanos. Essa técnica, a fertilização in vitro (FIV), heteróloga, homem/hamster, utilizava a inseminação de oócitos de hamster dourado sem zona pelúcida com espermatozóides humanos 
devidamente capacitados, com posterior cultura dos ovócitos penetrados em meios específicos, e a interrupção da primeira divisão do "zigoto", em metáfase, fase esta propícia para a análise.

Com o aprimoramento dessa técnica, por Mar$\operatorname{tin}^{(3)}$, a análise individualizada dos cromossomos de espermatozóides humanos, assim como das possíveis anomalias numéricas e estruturais, presentes nos mesmos, estimulou um novo campo de pesquisa na Citogenética Humana e na Genética Clínica.

\section{FREQÜÊNCIAS DE ANOMALIAS CRO- MOSSÔMICAS ENCONTRADAS EM ES- PERMATOZÓIDES DE INDIVÍDUOS NOR- MAIS}

Em revisão recente ${ }^{(4)}$, avalia-se que até esta data, mais de vinte mil (20.000) complementos cromossômicos de espermatozóides de indivíduos saudáveis foram analisados pelos oito (8) diferentes grupos de pesquisadores que dominam essa técnica: Martin et al. (Canadá( $\left.{ }^{(5,6,7)}\right)$, Brandriff et al. (Estados Uni$\operatorname{dos}^{(8,9)}$ ), Kamiguchi \& Mikamo (Japão ${ }^{(10)}$ ), Jenderny \& Röhrborn (Alemanha ${ }^{(11)}$ ), Templado et al. (Espanha $^{(12)}$ ), Pelestor (França ${ }^{(13)}$ ), Estop et al. (Estados Unidos $^{(14)}$ ) e Rosenbusch et al. (Alemanha ${ }^{(15)}$ ).

A incidência de complementos haplóides de espermatozóides com anomalias cromossômicas, estruturais variou, nos indivíduos estudados pelos grupos acima, de $0 \%^{(2)}$ a $13 \%^{(10)}$ com média de 6-7\%. A incidência de anomalias numéricas encontrada em complementos cromossômicos de espermatozóides de indivíduos saudáveis variou de 1 a 4\% (3,3\% - frequiência média de complementos hipo-haploides e 1,7\% freqüência média de complementos hiper-haploides). Tanto a hipo quanto a hiper-haploidia deveriam ocorrer em frequiências semelhantes, pois surgem por não disjunção meiótica. Entretanto, a hipoploidia é encontrada com uma freqüência mais elevada do que a hiper-haploidia, sendo, portanto, mais provável que esse evento ocorra, principalmente, pela perda artificial de cromossomos durante a fixação cromossômica, a qual é realizada, geralmente, pelo método de Tarkowski ${ }^{(16)}$. Portanto, por consenso, ficou estabelecido que para se calcular a freqüência de aneuploidias deve-se considerar uma estimativa conservadora, ou seja, a freqüência de hiper-haploidia multiplicada por dois (2), não se levando em consideração, para os cálculos totais, os complementos hipo-haploides encontrados.

\section{SEGREGAÇÃO MEIÓTICA EM INDIVÍ- DUOS PORTADORES DE TRANSLOCA- ÇÕES E INVERSÕES}

Essa técnica também tem sido utilizada para estudar os diferentes tipos de segregação cromossômica na meiose de indivíduos heterozigotos para anomalias estruturais, tais como translocações recíprocas e Robertsonianas e, inversões, já que estes têm um risco aumentado de produzir gametas com rearranjos não equilibrados. Na meiose de indivíduos heterozigotos para translocações Robertsonianas, o cromossomo translocado e seus dois homólogos normais formam uma figura trivalente, possibilitando diferentes segregações cromossômicas: a segregação alternada, que produzirá gametas com os dois cromossomos normais ou gametas balanceados, com o cromossomo translocado; a segregação adjacente, que produzirá gametas com o cromossomo translocado e um dos homólogos normais e a segregação 3:0, a qual produz gametas com os três (3) cromossomos envolvidos na translocação ou com ausência total desses cromossomos. Nos estudos realizados em indivíduos portadores de translocações Robertsonianas, observou-se que, independentemente dos cromossomos envolvidos na translocação, a grande maioria dos espermatozóides (72,2 a 96,7\%) seriam oriundos de segregação alternada, originando gametas normais e balanceados, com exceção do trabalho de Balkan \& Martin $^{(17)}$ que estudaram a t $(14 ; 21)$ e encontraram um grande excesso de complementos normais $(70,8 \%) \mathrm{em}$ comparação com complementos balanceados $(16,7 \%)$, provavelmente como conseqüência do pequeno número (24) de células analisadas ${ }^{(4)}$. Através da FIV heteróloga já foram estudadas translocações recíprocas, envolvendo todos os cromossomos do complemento haplóide masculino, com exceção dos cromossomos sexuais e do cromossomo $21^{(4)}$. As freqüências médias de gametas normais/com translocação equilibrada (segregação alternada) e com translocação não equilibrada (segregação adjacente) nos trinta e seis (36) portadores estudados foi de $46 \%$ e $54 \%$, respectivamente. Os complementos cromossômicos de espermatozóides analisados de indivíduos portadores de inversões pericêntricas e paracêntricas apresentaram um padrão de segregação meiótico, onde cromossomos normais e invertidos ocorriam. A presença de complementos haplóides, apresentando recombinação, foi observada nos casos em que a inversão cobria mais de $50 \%$ do tamanho total do cromossomo ${ }^{(4)}$. 


\section{OUTRAS APLICAÇÕES DA FIV HETERÓ- LOGA}

A FIV heteróloga, homem/hamster também tem sido utilizada na avaliação dos efeitos de agentes mutagênicos em células da linhagem germinativa de pacientes com câncer, tratados com rádio e/ou quimioterapia ou em espermatozóides expostos in vitro ${ }^{(18 / 23)}$. Os resultados desses estudos, em geral, demonstram um aumento na freqüência de anomalias estruturais em complementos haplóides de espermatozóides de indivíduos tratados, quando comparados com indivíduos do controle.

Na tentativa de testar a hipótese do efeito da idade paterna, independente da idade materna, na freqüência de aneuploidias, essa metodologia tem sido aplicada. Esse efeito não foi observado por Martin \& Rademaker ${ }^{(24)}$ para anomalias cromossômicas numéricas, entretanto a incidência de anomalias cromos- sômicas estruturais apresentou correlação positiva com a idade do doador, variando de $2,8 \%$, em indivíduos mais jovens, vinte a vinte e quatro (20-24) anos, a $13,6 \%$, em indivíduos com mais de quarenta e cinco (45) anos de idade. Outros pesquisadores ${ }^{(9,15,25)}$ também encontraram frequiências mais elevadas de anomalias estruturais com o aumento da idade do doador, mas não foram estatísticamente significativas.

\section{METODOLOGIA DETALHADA DA FIV HETERÓLOGA, HOMEM/HAMSTER}

Para implantarmos a FIV heteróloga em nosso laboratório, utilizamos a metodologia desenvolvida por Rudak et al. ${ }^{(2)}$ e Martin ${ }^{(3)}$, e seguimos o protocolo da Universidade Autônoma de Barcelona - Espanha (Profa. Dra. Cristina Templado, comunicação pessoal) detalhado na Figura 1.

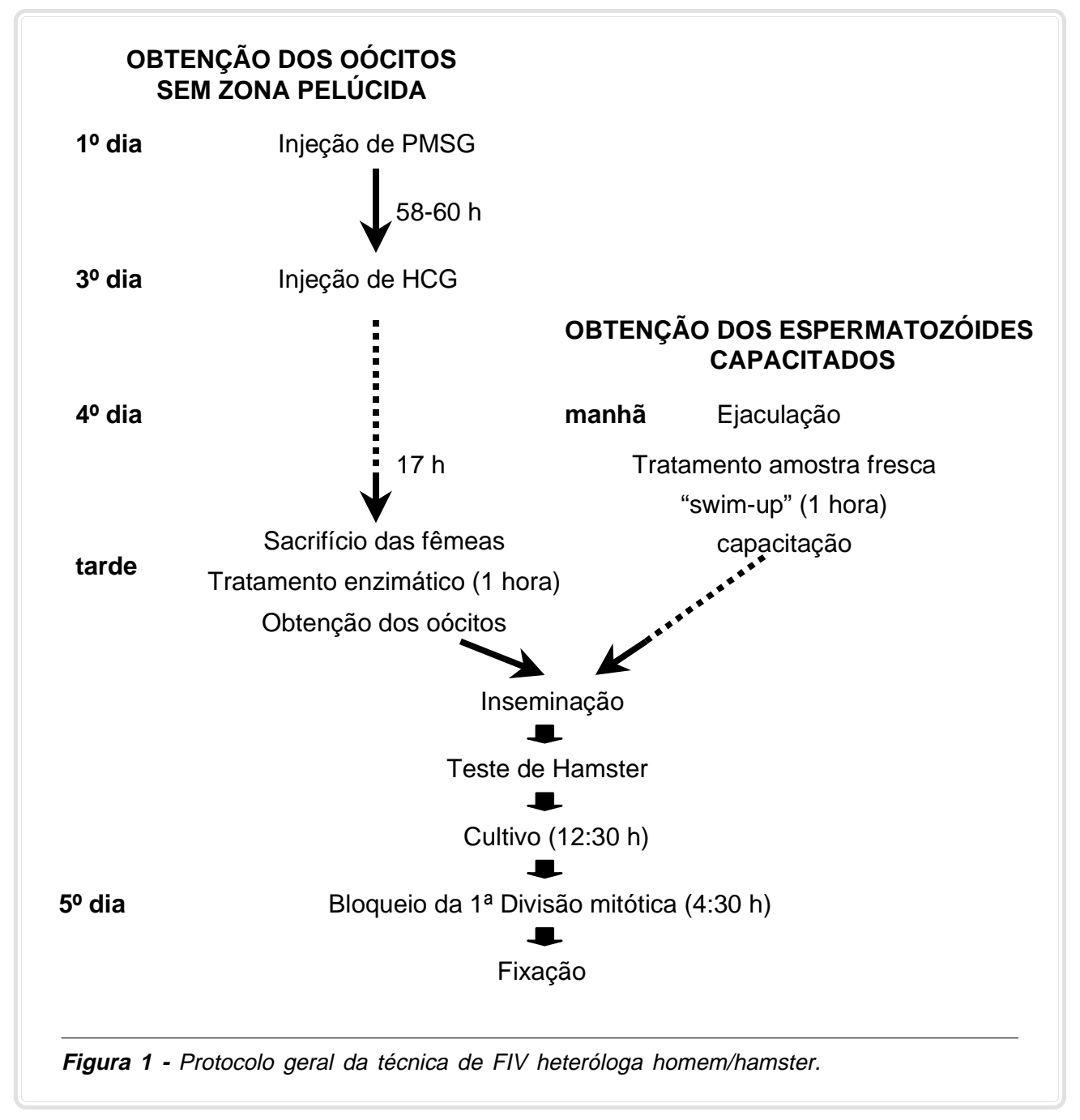




\subsection{Criação e Superovulação das fêmeas de hamster dourado (Mesocricetus auratus). Obtenção dos oócitos}

A necessidade de um grande número de oócitos de hamster, para maior rendimento da técnica de FIV heteróloga, exige que as condições em que as fêmeas são criadas sejam padronizadas. Estas são criadas no Biotério Geral da Faculdade de Medicina de Ribeirão Preto (USP), em uma sala especial, com temperatura controlada $\left(22\right.$ a $\left.24^{\circ} \mathrm{C}\right)$, período claro de catorze (14) horas e período escuro de dez (10) horas e separadas em caixas, de acordo com seu ciclo estral (máximo seis (06) fêmeas por caixa).

As fêmeas recebem um injeção intraperitoneal (i.p.) de 40 UI de PMSG (Pregnant Mare's Serum Gonadotrophin) no primeiro dia de seu ciclo estral, quando eliminam através do orificio vaginal, um muco amarelado, viscoso e de forte odor. Após cinqüenta e oito a sessenta (58-60) horas, recebem 40 UI de HCG (Human Chorionic Gonadotrophin), através de injeção i.p. Para a obtenção dos oócitos (16:30h após a injeção de HCG), as fêmeas são eterizadas e sacrificadas por deslocamento cervical, para a retirada dos oviductos e recolhimento da massa de células do cumulus oophorus. Submete-se essa massa de células a um tratamento com $0,1 \%$ de hialuronidase, em meio BWW $^{(26)}$, acrescido de $3 \mathrm{mg} / \mathrm{ml}$ de albumina humana, para a liberação dos oócitos (Figura 2). Estes são lavados em $\mathrm{BWW}_{3}$ e transferidos para $0,1 \%$ de tripsina, em meio $\mathrm{BWW}_{3}$, para a retirada da zona pelúcida e liberação do primeiro corpúsculo polar (Figura 3). Os oócitos são novamente lavados, em meio BWW 33 (acrescido de $33 \mathrm{mg} / \mathrm{ml}$ de albumina humana), estando prontos para a co-incubação (colocação dos oócitos com os espermatozóides). O tratamento enzimático dos oócitos é realizado no campo escuro de um microscópio estereoscópico e todo o procedi- mento, desde o sacrificio das fêmeas até a co-incubação, deve levar, no máximo, quarenta e cinco (45) minutos pois os oócitos podem sofrer partenogênese, que bloquearia uma futura penetração. A presença da placa metafásica (metáfase II) demonstra que o oócito está em condições de ser fertilizado.

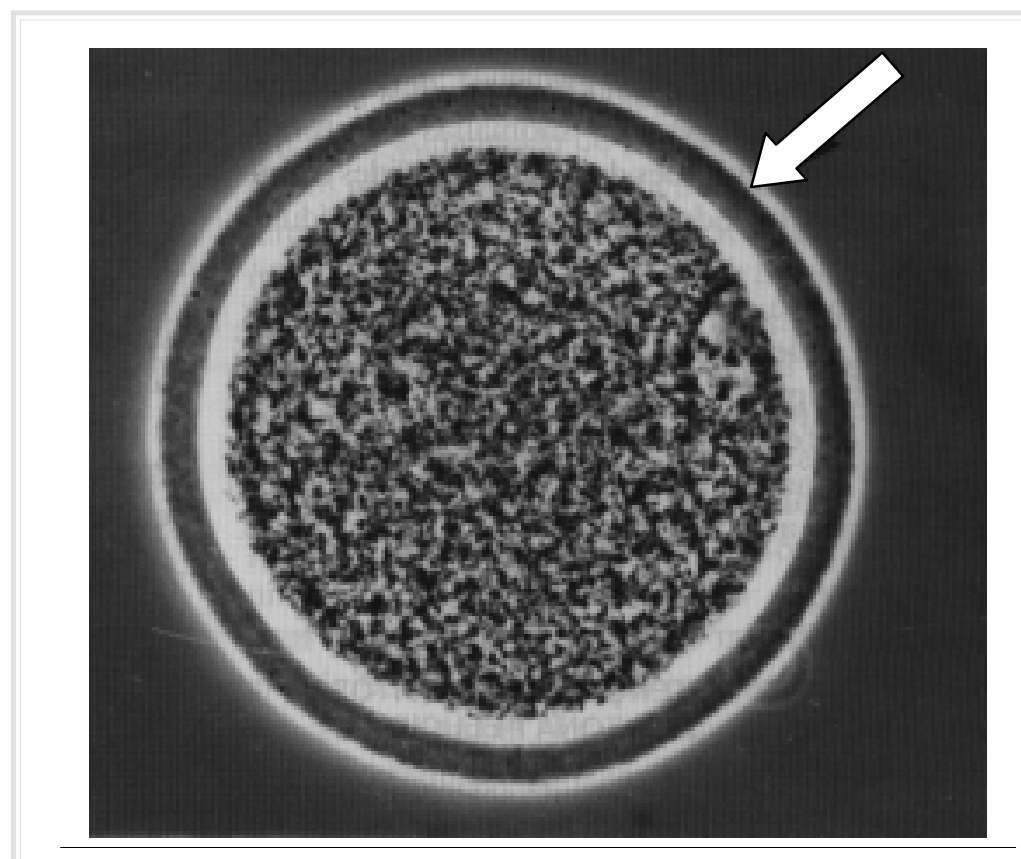

Figura 2 - Oócito de hamster dourado, após tratamento com hialuronidase. A seta indica a região da zona pelúcida.

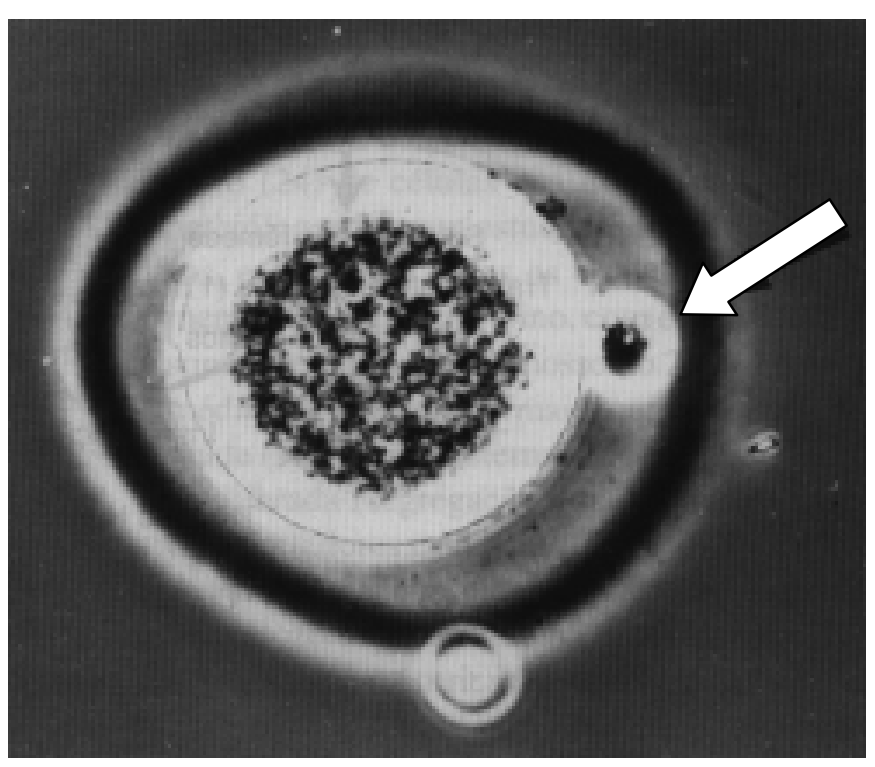

Figura 3 - Oócito de hamster dourado, durante tratamento com tripsina. Observa-se o início da expansão da zona pelúcida. A seta indica o $1^{\circ}$ corpúsculo polar. 


\subsection{Capacitação dos espermatozóides}

A coleta do sêmen é feita em frasco estéril, após dois a quatro (2-4) dias de abstinência sexual, e este é processado logo após a liquefação. Lava-se o sêmen (uma a três (1) a (3) vezes) com BWW ${ }_{3}$, centrifugando-se a seguir e descartando-se o sobrenadante, para a retirada do fluido seminal. Após a última lavagem, descarta-se o sobrenadante e coloca-se 0,5-1,0 $\mathrm{ml} \mathrm{de} \mathrm{BWW}_{3}$ sobre o sedimento, mantendo-se o tubo inclinado $\left(45^{\circ}\right)$ em estufa de $\mathrm{CO}_{2}(5 \%)$, à $37^{\circ} \mathrm{C}$, por uma (1) hora (método "swim-up"). Após esse período, retira-se o sobrenadante e centrifuga-se o mesmo. Faz-se a contagem do número de espermatozóides por ml (Câmara de Neubauer), leva-se à concentração ideal ( 1 a 3 x $10^{6}$ espermatozóides $/ \mathrm{ml}$ ) com $\mathrm{BWW}_{33}$. Preparam-se as placas de inseminação, com gotas $(0,2 \mathrm{ml})$ contendo a concentração ideal de espermatozóides, submersas em vaselina líquida. Essas placas deverão permanecer em estufa de $\mathrm{CO}_{2}(5 \%)$ à $37^{\circ} \mathrm{C}$, por um período de cinco (5) a sete (7) horas, para a capacitação dos espermatozóides. O preparo do sêmen, geralmente, é realizado no período da manhã, para que os espermatozóides já estejam capacitados no horário em que será feita a co-incubação

\subsection{Fertilização in vitro heteróloga e Teste de Hamster (TH)}

Os oócitos, que estão em metáfase II, sem zona pelúcida, são incubados com os espermatozóides nas gotas das placas de inseminação, para que ocorra a fertilização. Retornam-se as placas para a estufa de $\mathrm{CO}_{2}$, por um período de uma (1) hora, quando se deve iniciar os testes de hamster, para verificar-se a frequiência de oócitos penetrados. O TH consiste na colocação de três (3) a cinco (5) oócitos em lâmina, previamente lavada com álcool isopropílico e preparada com quatro (4) pequenas gotas de cera (cera de abelha 1:vaselina 9:parafina 1) onde a lamínula é colocada e pressionada para promover o achatamento dos oócitos, o que permite a visualização da "cabeça inchada" e cauda do espermatozóide, caso o oócito tenha sido penetrado (Figura 4). Quando a frequiência de ovócitos (oócitos penetrados) chega a $50 \%$, interrom- pe-se a co-incubação, lavando-se os mesmos em meio Ham F-10 complementado (L-glutamina, soro bovino fetal e antibióticos), para evitar a polispermia, que pode ser observada pela presença de várias cabeças inchadas no citoplasma do oócito.

\subsection{Cultivo dos ovócitos}

Os ovócitos são transferidos para o meio de cultivo (Ham F-10 complementado) e são mantidos em estufa de $\mathrm{CO}_{2}$ à $37^{\circ} \mathrm{C}$ por doze a treze (12-13) horas. Os espermatozóides que penetraram nos oócitos formam pronúcleos que podem ser observados 1:30 h após a fertilização ${ }^{(4)}$. A Figura 5 apresenta um ovócito (um (1) pronúcleo masculino e um (1) feminino) com a exclusão do segundo $\left(2^{\circ}\right)$ corpúsculo polar. O bloqueio da primeira ( $1^{\text {a }}$ ) divisão mitótica dos "zigotos" é feito com a transferência destes para meio Ham F-10 completo, suplementado com Colcemid $(0,04 \mathrm{mg} / \mathrm{ml})$ por 4:30-5:00 horas.

\subsection{Fixação}

Transferem-se os "zigotos" para uma solução hipotônica (citrato de sódio $1 \%$ ) à $37^{\circ} \mathrm{C}$ por cinco a seis (5-6) minutos e os mesmos são fixados pelo método de Tarkowsky ${ }^{(16)}$ em lâminas previamente lavadas com álcool isopropílico, com poucas gotas de fixador

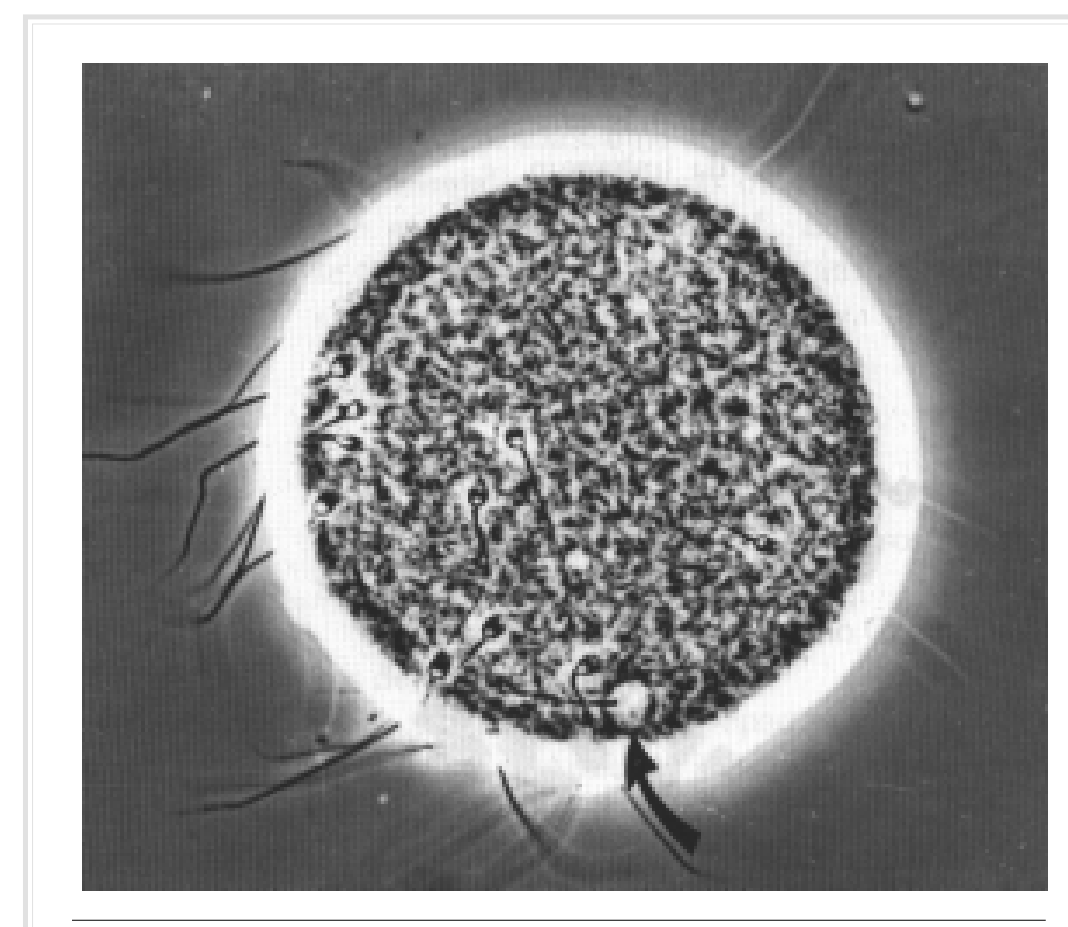

Figura 4 - Ovócito de hamster dourado. A seta indica a presença de "cabeça inchada" e da cauda do espermatozóide humano. 
(etanol 3:ácido acético 1). Alguns “zigotos” são fixados antes de atingir a metáfase. Outros, são fixados no devido tempo (Figura 6), sendo que as metáfases são analisadas em microscopia de contraste de fase ou com coloração convencional para serem avaliadas quanto à extensão dos cromossomos, separação das cromátides e presença (ou não) de citoplasma. Essa análise é importante para que se estabeleça o tempo de tratamento para bandar os cromossomos. germinativa de homens em risco genético, assim como possibilitará o estudo de indivíduos normais na população brasileira.

\subsection{Hibridação in situ por fluorescência, no es- tudo de aneuploidias}

O estudo citogenético do gameta masculino não tem sido realizado unicamente através de bandamento das metáfases obtidas após a FIV heteróloga, ho-

\subsection{Bandas G}

Aplicamos o tratamento utilizado atualmente na Universidade Autônoma de Barcelona (Dra. Cristina Templado, comunicação pessoal).

Lâminas envelhecidas por três a quatro (3-4) dias são tratadas com $2 x$ SSC à $62-64^{\circ} \mathrm{C}$, por dois a quatro (2-4) minutos e lavadas em água corrente. Depois de secas, são submetidas à coloração Wright (corante 1:tampão Sorensen 3), por dois a três (2-3) minutos. O complemento cromossômico haplóide do espermatozóide humano pode ser analisado, como demonstra a Figura 7.

A implantação dessa técnica em nosso laboratório, na Faculdade de Medicina de Ribeirão Preto (USP), propiciará melhor estimativa da probabilidade de transmissão de anomalias cromossômicas por células da linhagem

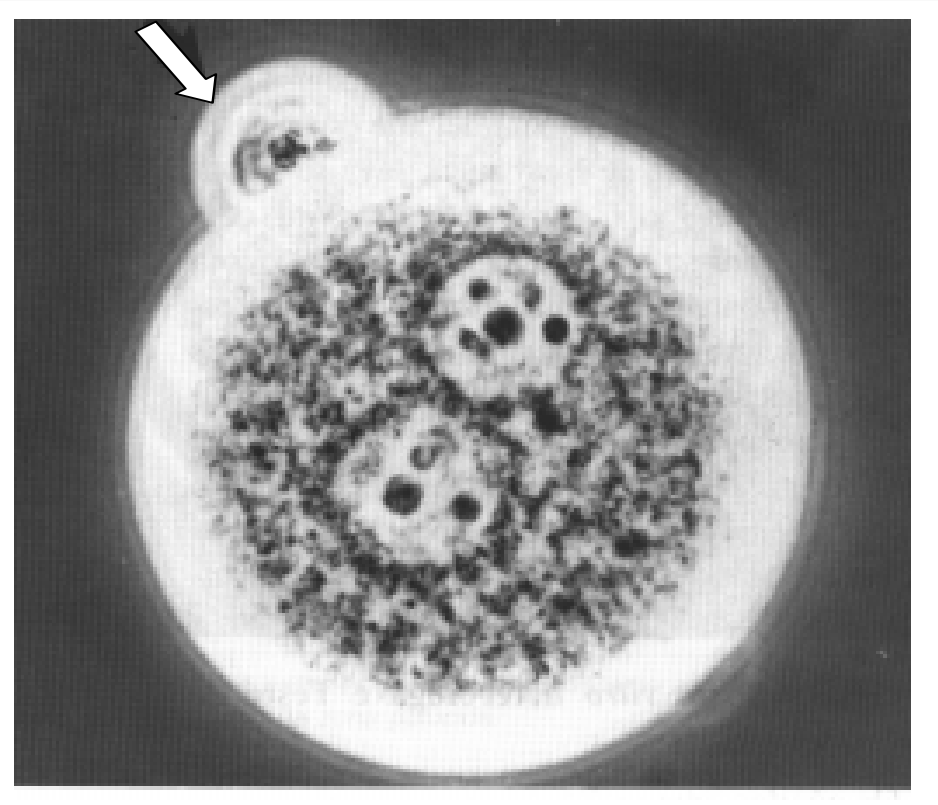

Figura 5 - Ovócito de hamster dourado com 2 pronúcleos (1 pronúcleo masculino e outro feminino). A seta indica a exclusão do $2^{\circ}$ corpúsculo polar.

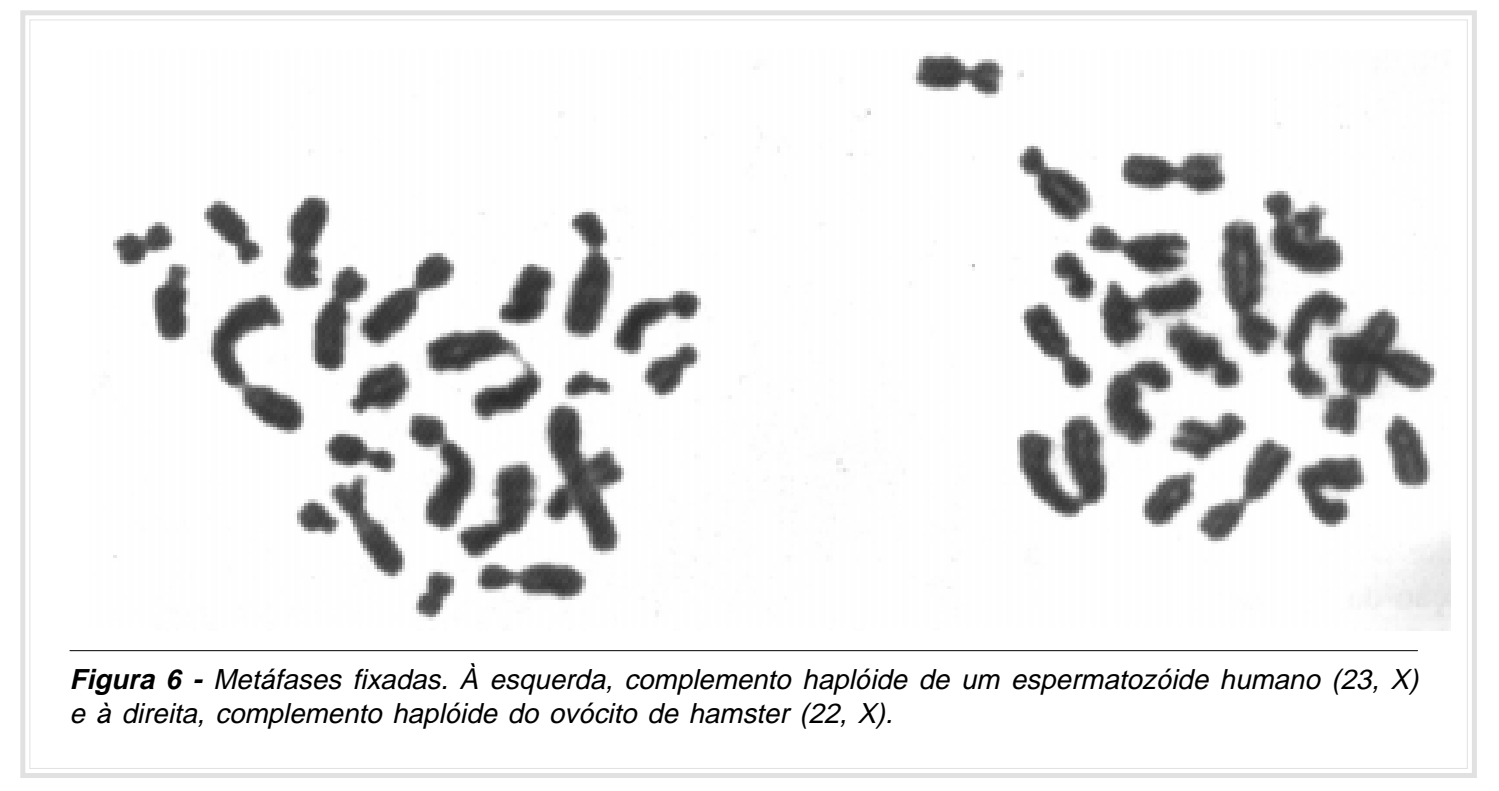




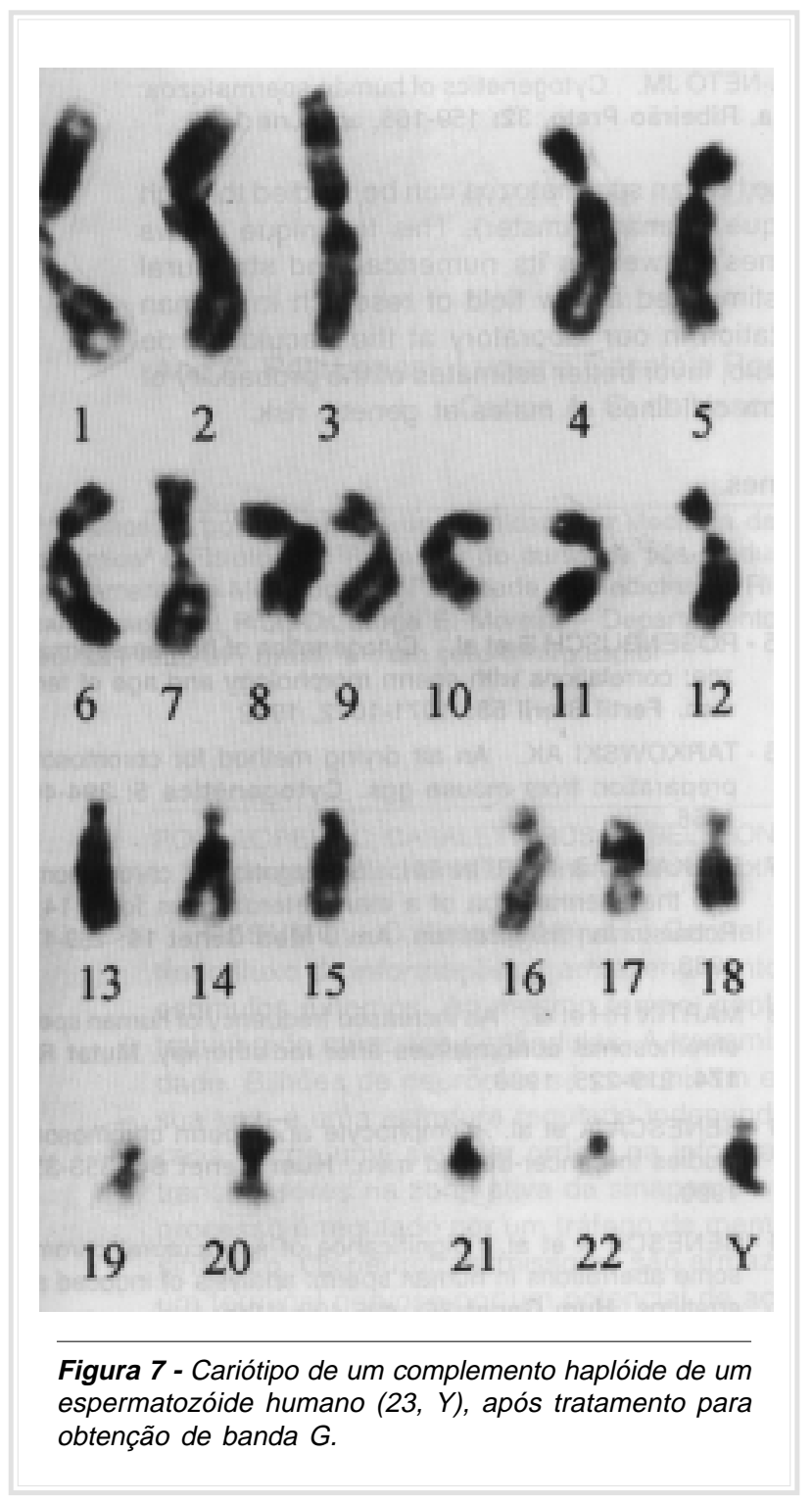

mem/hamster. A técnica de hibridação in situ por fluorescência (FISH) é, atualmente, utilizada para determinar aneuploidias em núcleos interfásicos de espermatozóides e em pronúcleos derivados de espermatozóides, após a FIV heteróloga.

A hibridação in situ foi testada em 1990, pela primeira vez, em núcleos interfásicos de espermatozóides humanos por Pieters et al. e por Guttenbach \& Schmid, quando estudaram as freqüências de dissomia dos cromossomos 1 e Y, respectivamente ${ }^{(4)}$. A utilização de uma única sonda pode comprometer os resultados, pois a falta de sinal fluorescente pode representar uma nulissomia do cromossomo em estudo, mas, também, pode ocorrer devido ao fracasso na hibrida- ção, em uma determinada célula. Por outro lado, o aparecimento de dois sinais próximos pode representar uma dissomia ou uma diploidia. Uma visualização eficiente de complementos diplóides pode ser realizada, quando se utilizam duas (2) sondas de DNAs alfa-satélites, específicos de autossomos, ou uma (1) sonda específica de um autossomo e sondas X e Y, simultaneamente ${ }^{(4)}$. A freqüência de aneuploidia é estimada inclusive entre espermatozóides imóveis ou mortos.

A utilização de FISH em pronúcleos de espermatozóides, obtidos após uma modificação da técnica de FIV heteróloga, homem/hamster também está sendo utilizada no estudo de aneuploidias dos gametas masculinos humanos ${ }^{(27)}$, determinando as freqüências dessas alterações em espermatozóides móveis, capazes de penetrar em oócitos de hamster sem zona pelúcida.

\section{CONSIDERAÇÕES FINAIS}

A FIV heteróloga, homem/hamster é considerada uma metodologia cara, trabalhosa e com um rendimento de complementos haplóides relativamente baixo, mas a única que permite o estudo completo da constituição dos cromossomos do espermatozóide humano; a hibridação in situ por fluorescência não permite a análise completa da constituição cromossômica do espermatozóide humano, mas somente de um número reduzido de cromossomos, dependendo das sondas utilizadas, uma a três ( 1 a 3 ), sendo que outras anomalias numéricas ou estruturais presentes não podem ser detectadas ${ }^{(4)}$. Essas metodologias se complementam, fornecendo informações valiosas sobre a linhagem germinativa dos indivíduos estudados.

\section{AGRADECIMENTOS}

Agradecemos à FAPESP, processos n. 88/0751-2; 88/3089-9; 92/3085-9

Agradecemos à CAPES e ao CNPq, pelas bolsas de estudo concedidas.

Agradecemos ao Departamento. de Genética e Matemática Aplicada à Biologia da Faculdade de Medicina de Ribeirão Preto.

Agradecemos ao Departamento de Biologia Celular da Faculdade de Medicina da Universidade Autônoma de Barcelona, na pessoa da Dra. Cristina Templado. 
SARTORELLI EMP; PAIVA WJM; MAZZUCATO LF. \& PINA-NETO JM. Cytogenetics of human spermatozoa: human/hamster in vitro fertilization technique. Medicina, Ribeirão Preto, 32: 159-166, apr./june 1999.

ABSTRACT: The chromosomal constitution of the human spermatozoa can be studied through the heterologous "in vitro" fertilization (FIV) technique (human/hamster). This technique allows the identification of the human sperm chromosomes as well as its numerical and structural analyses. The improvement of this technique has stimulated a new field of research in Human Cytogenetics and in Clinical Genetics. Its implantation in our laboratory at the Faculdade de Medicina de Ribeirão Preto, Universidade de São Paulo, favor better estimates of the probability of the transmission of chromosomal anomalies by germ cell lines of males at genetic risk.

UNITERMS: Human. Spermatozoa. Chromosomes.

\section{REFERÊNCIAS BIBLIOGRAFICAS}

1 - YANAGIMACHI R; YANAGIMACHI H \& ROGERS, B. The use of zona-free animal ova as a test system for the assessment of the fertilizing capacity of human spermatozoa. Biol Reprod 15: 471-476, 1976.

2 - RUDAK E; JACOBS PA \& YANAGIMACHI R. Direct analysis of the chromosome constitution of human spermatozoa. Nature 274: 911-913, 1978.

3 - MARTIN RH. A detailed method for obtaining preparations of human sperm chromosomes. Cytogenet Cell Genet 35: 252-256, 1983.

4 - GUTTENBACH M; ENGEL W \& SCHMID M. Analysis of structural and numerical chromosome abnormalities in sperm of normal men and carriers of constitutional chromosome aberrations. A review. Hum Genet 100: 1-21, 1997.

5 - MARTIN RH et al. Direct chromosomal analysis of human spermatozoa: preliminary results from 18 normal men. Am J Hum Genet 34: 459-468, 1982.

6 - MARTIN RH et al. The chromosome constitution of 1000 human spermatozoa. Hum Genet 63: 305-309, 1983.

7 - MARTIN RH et al. Variation in the frequency and type of sperm chromosomal abnormalities among normal men. Hum Genet 77: 108-114, 1987.

8 - BRANDRIFF BF et al. Chromosomal abnormalities in human sperm: Comparisons among four healthy men. Hum Genet 66:193-201, 1984.

9 - BRANDRIFF BF et al. Chromosomes of human sperm: variability among normal individuals. Hum Genet 70: 18-24, 1985.

10 - KAMIGUCHI Y \& MIKAMO K. An improved, efficient method for analyzing human sperm chromosomes using zona-free hamster ova. Am J Hum Genet 38: 724-740, 1986.

11 - JENDERNY $\mathrm{J} \&$ RÖHRBORN G. Chromosome analysis of human sperm. I. First results with a modifield method. Hum Genet 76: 358-388, 1987.

12 - TEMPLADO $\mathrm{C}$ et al. Human sperm chromosomes. Hum Reprod 3: 133-138, 1988.

13 - PELLESTOR F. Differential distribuition of aneuploidy in human gametes according to their sex. Hum Reprod 6: 1252-1258, 1991.

14 - ESTOP AM et al. Cytogenetic studies in human sperm. Hum Genet 87: 447-451, 1991.
15 - ROSENBUSCH B et al. Cytogenetics of human spermatozoa: correlations with sperm morphology and age of fertile men. Fertil Steril 58: 1071-1072, 1992.

16 - TARKOWSKI AK. An air drying method for chromosome preparation from mouse ggs. Cytogenetics 5: 394-400, 1966.

17 - BALKAN W \& MARTIN RH. Segregation of chromosomes into the spermatozoa of a man heterozygous for a $14 ; 21$ Roberstonian translocation. Am J Med Genet 16: 169-172, 1983.

18 - MARTIN RH et al. An increased frequency of human sperm chromosomal abnormalities after radiotherapy. Mutat Res 174: 219-225, 1986.

19 - GENESCÀ A et al. Lymphocyte and sperm chromosome studies in cancer-treated men. Hum Genet 84: 353-355, 1990.

20 - GENESCÁ A et al. Significance of sctrucutural chromosome aberrations in human sperm: analysis of induced aberrations. Hum Genet 85: 495-499, 1990

21 - JENDERNY $\mathrm{J}$ et al. Chromosome aberrations in 450 sperm complements from eight controls and lack of increase after chemotherapy in two pacients. Hum Genet 90: 151-154, 1992.

22 - ROUSSEAUX S et al. Immediate rearrangement of human sperm chromosomes following in-vivo irradiation. Hum Reprod 8: 903-907, 1993.

23 - KAMIGUCHI Y et al. Chromosome analysis of spermatozoa exposed to antineoplasic agents in vitro. Mutat Res 326: 185-192, 1995

24 - MARTIN RH \& RADEMAKER AW. The effect of age on the frequency of sperm chromosomal abnormalities in normal men. Am J Hum Genet 41: 484-492, 1987.

25 - ESTOP AM et al. An analysis of human sperm chromosome breakpoints. Am J Hum Genet 56: 452-460.

26 - BIGGER JD et al. The culture of mouse embryos in vitro. In:DANIEL JC. Methods in mammalian embriology. Freeman, San Francisco, p. 86-116, 1971.

27 - MARTÍNEZ-PASARELL $O$ et al. Analysis of human spermderived pronuclei by three-colour fluorescent in-situ hybridization. Hum Reprod 12: 641-645, 1997.

Recebido para publicação em 18/12/98

Aprovado para publicação em 06/04/99 